УДК 621.391

\title{
РАСПРЕДЕЛЕНИЕ АБСОЛЮТНОГО МАКСИМУМА ДИФФЕРЕНЦИРУЕМОГО В СРЕДНЕКВАДРАТИЧЕСКОМ ГАУССОВСКОГО СТАЦИОНАРНОГО ПРОЦЕССА
}

\author{
Д. В. ЕВГРАФОВ \\ Национальный технический университет Украинь \\ «Киевский политехнический институт имени Игоря Сикорского», \\ Украина, Киев, 03056, пр-т Победы 37
}

\begin{abstract}
Аннотация. В работе найдено распределение абсолютного максимума дифференцируемого в среднеквадратическом стационарного гауссовского процесса интегрированием результатов решения второго уравнения Колмогорова. Показан путь, упрощающий интегрирование и его взаимосвязь с интегро-дифференциальным уравнением, полученным ранее. Впервые решено второе уравнение Колмогорова для граничных условий, позволяющих отыскать результат в виде бесконечного ряда с коэффициентами, найденными решением задачи Штурма-Лиувилля и сводящегося к простому выражению. Проанализирована взаимосвязь полученных результатов с ранее известными. Проведен сравнительный анализ корреляционных функций и выражений для распределений абсолютных максимумов дифференцируемого в среднеквадратическом и однокомпонентного марковского процессов. Несмотря на то, что корреляционная функция однокомпонентного марковского процесса может рассматриваться как предельное выражение для корреляционной функции дифференцируемого в среднеквадратическом процесса, выражения для распределений их абсолютных максимумов существенно разнятся. Это показывает практическую ценность результатов, поскольку реальные процессы в радиотехнических системах могут быть только дифференцируемыми в среднеквадратическом.
\end{abstract}

Ключевые слова: теория обнаружения; марковский процесс; второе уравнение Колмогорова; абсолютный максимум

Рассмотрим установившийся процесс $\lambda(s)$ на конденсаторе, последовательно соединенным с индуктивностью и сопротивлением (рис. 1), на вход которых подан белый гауссовый шум $n_{0}(s)$ с односторонней спектральной плотностью мощности $N_{0}$.

Корреляционная функция процесса $\lambda(s)$ имеет вид [1]:

$$
\begin{gathered}
B(\tau, \gamma)=\sigma^{2} \exp (-\gamma|\tau|)\left[\cos (\beta \tau)+\frac{\gamma}{\beta} \sin (\beta|\tau|)\right], \\
\beta=\sqrt{\omega_{2}-\gamma^{2}},
\end{gathered}
$$

где $\sigma^{2}=N_{0} /(2 R C)$ - дисперсия процесса, $\omega_{2}=1 /(L C)$ - второй спектральный момент процесса, $\gamma=R /(2 L)$ - некоторая вещественная положительная константа.

Пусть сформированный процесс $\lambda(s)$ подается на компаратор с порогом срабатывания $h$ и необходимо отыскать вероятность того, что за время наблюдения $t$ не произойдет ни одного срабатывания устройства. Искомая вероятность является распределением абсолютного максимума (PAM) стационарного дифференцируемого в среднеквадратическом гауссовского процесса $F_{0}(h, t)$. 


\section{БИБЛИОГРАФИЧЕСКИЙ СПИСОК}

1. Свешников A. А. Прикладные методы теории случайных функций / А. А. Свешников. - 2-е, перераб. и доп. - М. : ГРФМЛ, 1968. — 463 с.

2. Rice S. O. Mathematical analysis of random noise / S. O. Rice // BSTJ. - Jan. 1945. - Vol. 24, No. 1. - P. 46-156. - DOI : 10.1002/j.1538-7305.1945.tb00453.x.

3. Cramer $H$. A limit theorem for the maximum values of certain stochastic processes / $\mathrm{H}$. Cramer // Theory Probab. Appl. - 1965. - Vol. 10, No. 1. - P. 126-128. - DOI : $10.1137 / 1110012$.

4. Leadbetter $M$. R. Extreme value theory for continuous parameter stationary processes / M. R. Leadbetter, Holger Rootzen // Wahrscheinlichkeitstheorie verw Gebiete. - May 1982. - Vol. 60, No. 1. - P. 1-20. - DOI : 10.1007/BF01957094.

5. Leadbetter M. R. Extreme and Related Properties of Random Sequences and Processes / M. R. Leadbetter, Georg Lindgren, Holder Rootzen. - N. Y. : Springer, 1983. — DOI : 10.1007/978-1-4612-5449-2.

6. Галамбош Я. Асимптотическая теория порядковых статистик / Пер. с англ. ; под ред. В. В. Петрова. - М. : Наука, ГРФМЛ, 1984. — 304 с.

7. Кендалл М. Теория распределений / М.Кендалл, А.Стьюарт ; пер. с англ. В.В.Сазонова, А. Н. Ширяева под ред. А.Н.Колмогорова. - М. : Наука, ГРФМЛ, 1966. — 588 с.

8. Тихонов В. И. Марковские процессы / В.И.Тихонов, М.А.Миронов. - М. : Сов. радио, 1977. $488 \mathrm{c}$.

9. Евграфов Д. В. Распределение абсолютного максимума гауссовского марковского стационарного процесса / Д. В. Евграфов // Известия вузов. Радиоэлектроника. — 2013. - Т. 56, № 1. — С. 58-64. — Peжим доступа

http://radio.kpi.ua/article/view/S0021347013010068.

10. Евграфов Д. В. Интегрально-дифференциальное уравнение для распределения абсолютного максимума гауссовского стационарного процесса // Известия вузов. Радиоэлектроника. — 2003. - Т. 46, № 5. C. $25-30$.

11. Бейтмен Г. Высшие трансцендентные функции. Функции Бесселя, функции параболического цилиндра, ортогональные многочлены / Г. Бейтман, А.Эрдейн ; пер. с англ. Н. Я. Виленкина. - М. : Наука, ГРФМЛ, 1966. - $296 \mathrm{c}$.

12. Свграфов Д. В. Розподілення абсолютного максимуму в теорії виявлення сигналів / Д. В. Євграфов // Труди академії. — К. : МОУ, НАОУ, 2005. № 65 . - С. $86-89$. 
Распределение абсолютного максимума дифференцируемого в среднеквадратическом гауссовского стаиионарного процесса

13. Бакут B. A. Теория обнаружения сигналов / В. А. Бакут. - М. : Радио и связь, 1984. - 439 с.

14. Трифонов А. П. Совместное различение сигналов и оценка их параметров на фоне помех / А. П.
Трифонов, Ю. С. Шинаков. - М. : Радио и связь, 1986. $-236 \mathrm{c}$

Поступила в редакцию ? По-сле переработки question 